\title{
Socialising on a Skywalk: How Hong Kong's elevated walkways become public open spaces
}

\author{
Caterina Villani , Gianni Talamini
}

\author{
Department of Architecture and Civil Engineering, \\ City University of Hong Kong, Tat Chee Avenue, Kowloon, Hong Kong SAR, China \\ cvillani2-c@my.cityu.edu.hk, gianntal@cityu.edu.hk \\ Tel: +852 62244234
}

\begin{abstract}
In high-density Asian cities, the increasing scarcity of public open spaces gives rise to the need for stationary activities to tap into spaces originally conceived exclusively to channel pedestrian movements, such as grade separation pedestrian systems. However, the types and patterns of stationary activities on elevated walkways remain mostly unexplored. This study focuses on Hong Kong, wherein the scarcity of public open space characterises an extreme condition and where the burden of this scarcity falls most heavily on disadvantaged social groups, such as migrant workers. The findings highlight the prevalence of socially oriented activities and the importance of food as a gathering factor.
\end{abstract}

Keywords: Grade separation pedestrian system; Elevated pedestrian network; Public open space; Migrant domestic worker; Hong Kong

eISSN 2514-751X @ 2020 The Authors. Published for AMER ABRA cE-Bs by e-International Publishing House, Ltd., UK. This is an open-access article under the CC BY-NC-ND license (http://creativecommons.org/licenses/bync-nd/4.0/). Peer-review under responsibility of AMER (Association of Malaysian Environment-Behaviour Researchers), ABRA (Association of Behavioural Researchers on Asians) and cE-Bs (Centre for EnvironmentBehaviour Studies), Faculty of Architecture, Planning \& Surveying, Universiti Teknologi MARA, Malaysia.

DOI: https://doi.org/10.21834/aje-bs.v5i15.361 


\subsection{Introduction}

Due to the growing demand for mobility, urban spaces, especially transportation environments, have been degraded from being commons to mainly a resource for the circulation of transport modes (Nikolaeva et al., 2019). Subsequently, academic research, international organisations, and planning practice increasingly recognise that urban spaces will need to cater to mobility functions - mobile uses - as well as public space functions stationary activities - in cities worldwide (Agyeman \& Zavestoski, 2015; UN-Habitat, 2013). Specifically, mobility transition studies (Nikolaeva et al., 2019) recommend reconceptualising urban spaces, so as to balance movement by different modes of transport (pedestrians, bicycles, and motorised vehicles) as well as lingering and other stationary uses (social interactions and cultural expressions) in the planning of urban streets (Von Schönfeld \& Bertolini, 2017), transport stations, and pedestrian networks.

Grade separation pedestrian systems (GSPS) include underground pedestrian systems (UPS) and elevated pedestrian networks (EPNs) (often referred to as skywalks or elevated walkways) and well-characterised spaces planned to accommodate pedestrian mobility (Robertson, 1993; Tan \& Xue, 2014). These networks commonly interconnect high-rise commercial or office buildings with activity hubs, such as transport stations, in the dense urban core of numerous cities worldwide. GSPS are proposed both as solutions to congested traffic street networks and as means to enhance pedestrian access to shopping precincts (Cui, Allan, \& Lin, 2013; Robertson, 1993). Although it was initially implemented in North American cities, the EPNs of high-density Asian cities such as Hong Kong, Shanghai, Mumbai, Singapore, Kuala Lumpur, and Bangkok have experienced increased development over the past 40 years. Relevant studies demonstrated that EPNs significantly improve mobility and the economic activity of the surrounding urban areas (Corbett, Xie, \& Levinson, 2009; Wan, 2010). Furthermore, in conditions of high population density and low public open space provision, the temporary occupation of EPN spaces for stationary activities is increasingly becoming a viable informal response to the socializing necessities of vulnerable social groups.

In Hong Kong, migrant domestic workers (MDWs) (often referred to as foreign domestic helpers) are required to reside by their employers, and are facing an extreme shortage of available public open spaces as gathering places during their day off (typically Sunday). The employment of MDWs was made possible by a 1973 policy, and their number grew in the following decade, and boomed during the 1990s, reaching 157000 in 1995. Despite a deceleration of the pace of growth, their number as of 2016 is 352000 , and is still rising. Based on statistics made available by the Census and Statistics Department, MDWs are currently accounting for $9.3 \%$ of the total workforce, indicating their essential contribution to the local economy. The Philippines are the largest supplier of this workforce, accounting for $54 \%$ of the overall MDWs, followed by Indonesia, which accounts for $44 \%$. The remaining $2 \%$ of MDWs come from South and Southeast Asia. Nearly the entire population of MDWs is composed of females (99\%) aged $25-44(80 \%)$.

The impact of GSPS on public space provision in North American cities has raised issues related to the overall design scarcely incorporating planning for stationary activities, 
the limited availability of public services and facilities, and the controlled or denied access to privately-managed pedestrian environments by marginalised social groups (Maitland, 1992; Robertson, 1993; Terranova, 2009). Similarly, empirical findings concerning Asian cities' UPS indicated an inadequate availability of public facilities and the prevalence of short duration transit-oriented activities (Cui, Allan, Taylor, \& Lin, 2013). Besides, an evidence-based analysis of the stationary activity patterns of EPNs remains mostly unexplored. This study investigates the EPNs of Hong Kong, well-known internationally for its comprehensive EPN system, by focussing on the case of the EPN in Mong Kok (MK). The district is one of the city's densest and most commercially active, and its provision of public space is sub-standard (Xue, Manuel, \& Chung, 2001). The MK EPN emerged as a particularly representative case for the substantial level of stationary use by MDWs observed during preliminary site visits. First, this study illustrates the network development rationale and the accessibility to services provided by it. Second, as a novel setting for environment-behaviour research, it analyses stationary activities during the peak hours of the day during weekends, when MDWs assemble in this space.

In this paper, our research questions are as follows:

1) How many stationary activities can the EPN cater to?

2) How do these stationary uses vary with weather conditions?

3) Which types of stationary activities are observable in the EPN?

4) Which design features or activities influence occupation patterns?

5) To what extent does the EPN environment support these recurring patterns of behaviour?

This study attempts to contribute to the limited literature on the impact of GSPS on public space provision in the Asian context. Additionally, it provides useful insights for an inclusive approach to the design of EPNs in the future, taking stationary activities into account.

\subsection{Literature Review}

Over the last decade, relevant research has been focussing on the impact of GSPS on public space provision, especially in North American cities (Cui, Allan, \& Lin, 2013). Notable studies assessed these through the contribution of GSPS strategies to:

1) The design for the provision of public open spaces,

2) The availability of public services and amenities, and

3) Access to these pedestrian environments by marginalised social groups.

The GSPS are studied as environments primarily designed to accommodate pedestrian flow, without sitting and resting opportunities (Robertson, 1993). In addition, GSPS are mainly developed in privately-owned and managed environments (e.g., commercial centres), and this poses some challenges to its wide public access after the buildings' opening hours (Robertson, 1993). Although the indoor environments there might be publicly accessible services, their use by social groups with a low buying power made the buildings' management limit access to these amenities, as in Montreal (Maitland, 1992). Research 
suggests that through GSPS, the physical separation from street-level public spaces and exclusive connection with office or high-end commercial buildings might result in social segregation, as observed in several US cities (Terranova, 2009). Limited research is being undertaken with respect to the impact of GSPS on public space provision in high-density Asian cities (Cui, Allan, \& Lin, 2013), where the development of GSPS is booming. In Tokyo, Osaka, Hong Kong, Shanghai, and Mumbai, the GSPS was introduced as a pedestrian and vehicular traffic separation measure. The GSPS soon became a space for the local elite in Mumbai (Harris, 2018). In Shanghai and Hong Kong, GSPS eventually turned into a means to establish a landscape of consumption between shopping centres (Tan \& Xue, 2014; Villani, 2018; Zacharias \& He, 2018). This is also evident in the underground system design of Shanghai, and presents an inadequate availability of public facilities and access points (Cui, Allan, Taylor, et al., 2013).

From the limited studies of GSPS in Asian cities, it also emerged that when the pedestrian flow reduces outside office hours, these mobility spaces might be used for a variety of stationary uses by different social groups in need of space (Harris, 2018). In Shanghai, homeless people use some underground systems as a sheltered sleeping place during the night (Cui, Allan, Taylor, et al., 2013). Similarly, in Mumbai, 'slum' residents use the skywalk above their neighbourhood to sit and relax after office hours (Harris, 2018). In Hong Kong, the setting of this study, similar phenomena are more visible and involve several urban districts that every Sunday become places of MDWs' social and cultural gatherings (Law, 2001; Villani, Zordan, Talamini, \& Cheng, 2019; Wang, Siu, \& Wong, 2016). During the Sunday closure of offices and public services, MDWs' stationary occupations - socializing, sharing food, sleeping, dancing, parading, reading, or praying emerge mainly in centrally located transit-oriented spaces such as the streets and the EPNs near railway or bus stations (Law, 2001; Tillu, 2011). The intensity and duration of these outdoor activities, as well as the weekly recurrence of what was named "Little Manila" is recognised as a part of Hong Kong's transnational cultural landscape (Law, 2002).

\subsection{Research Approach and Methodology}

This paper adopts a case study approach. This is suitable when the knowledge obtainable from the case study can potentially advance the understanding of a specific topic (Yin, 1984). Since the literature reveals that, in the Asian context, research on the impact of GSPS' development is limited, and the research on stationary uses of EPNs is unexplored, a case study is considered appropriate. Specifically, Cui et al. (2013) support the case study research on EPNs, suggesting the consideration of the "special and unique social situations of each city [...] because the effects of GSPS were highly dependent on the individual milieu" (p.159). This study was set in Hong Kong, internationally recognised as one of the most dense cities in the world. Hong Kong is characterised by a vertical and compact urban form, which since the 1960s triggered the development of multilevel pedestrian networks that connect commercial or office buildings and activity or transportation hubs (Tan \& Xue, 2014). In total, there are around 700 elevated pedestrian 
bridges in Hong Kong (Wang et al., 2016). At the same time, it is recognised that public open space is a quantitatively and qualitatively limited resource in the city (Rossini, 2019; Tang, 2017). This is observed to be a well-established setting for large gatherings of MDW groups - mainly young women from Southeast Asia - every Sunday, which is their stipulated day off (Law, 2001).

\subsection{Case Study}

The EPN in MK, Kowloon peninsula, was selected as a "revelatory case" (Yin, 1984) of the EPNs in Hong Kong. MK is an old urban neighbourhood with mixed land-use in the district of Yau Tsim Mong (Fig.1a). It is characterised by a combination of tall commercial and residential buildings and is a highly popular commercial destination for locals and tourists. MK is a major transport interchange for public transportation, with two railway stations: MK station and MK East station. With a high population density of $82,151 / \mathrm{km}^{2}$ (HKSAR Census and Statistics Department, 2016) and an extremely sub-standard public open space provision of 8.1 hectares (Xue et al., 2001), MK exemplifies an extreme urban condition.

The MK EPN construction was funded by a private developer, the Sun Hung Kei Properties Charitable Fund Limited, and it was completed in 2003 (P. Lam \& Kung, 2004). The purpose of the network was to provide higher pedestrian accessibility between the two railway stations and the connected commercial property, MOKO mall, owned by the developer. The EPN (Fig.1b) spans about 400m along two traffic arteries, MK Road and Sai Yee Street. The widths of the walkway are $8.5 \mathrm{~m}$ along MK Road and $5.5 \mathrm{~m}$ along Sai Yee Street. The EPN can be accessed through escalators or staircases situated in six locations along MK Road, and lifts were installed in four locations. The first part, across MK Road, is linked to the B3 exit of MK station, while the second part across Sai Yee Street is linked to the MOKO shopping mall and MK East station. Although the construction of the MK EPN was supported by a private developer to attract and channel pedestrian flow between transport stations and commercial complexes, the EPN is categorised as a public space, managed and maintained by the HK Government. This makes the place an accessible destination for the MDWs' leisure activities. It also caters to the MDWs commercial demands (Fig.1). 


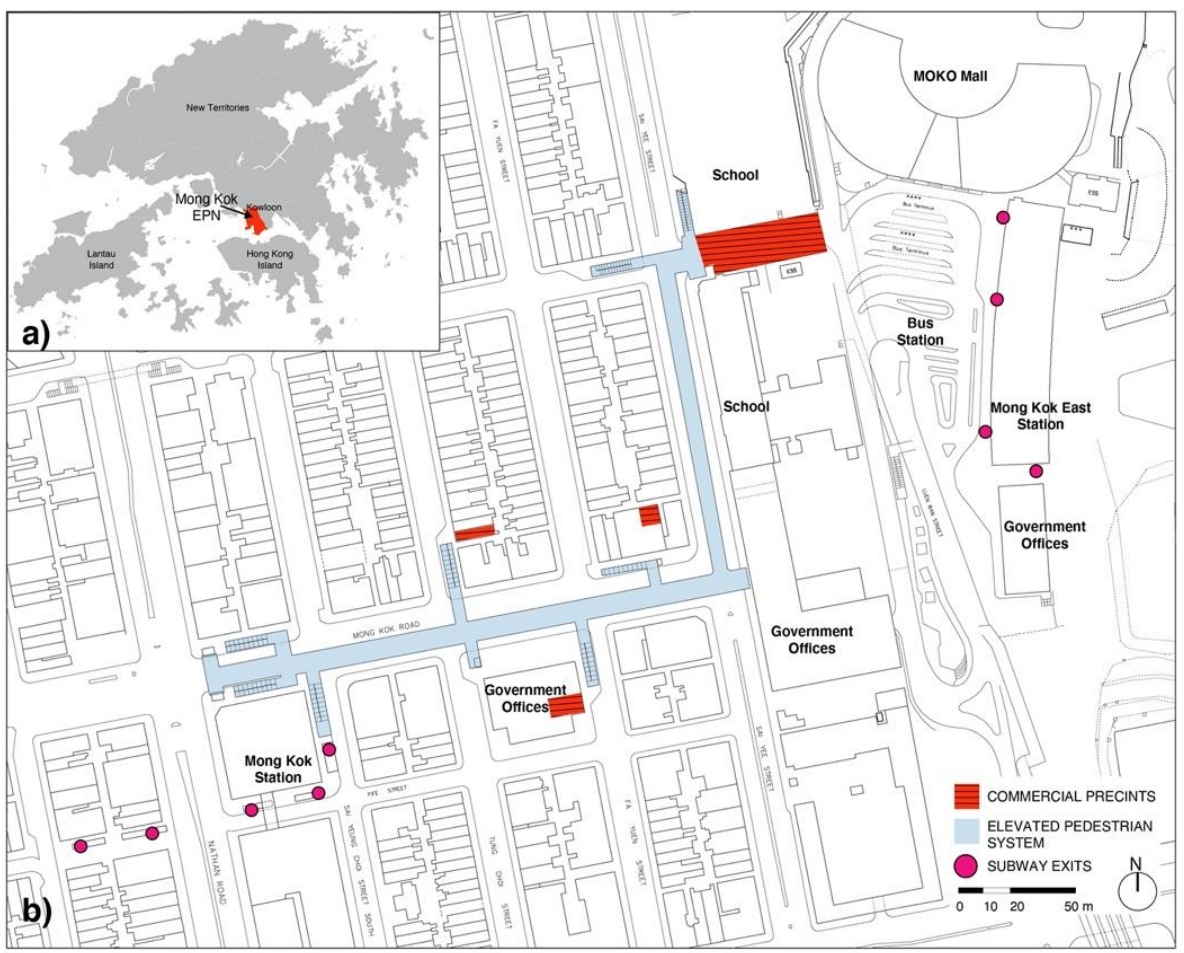

Fig. 1: a) Location of MK EPN in Yau Tsim Mong District. B) Map of MK EPN (Source: Caterina Villani based on Hong Kong OZP)

\subsection{Videography and Behavioural Mapping}

This study applied two tools of environment-behaviour research: videography (and snapshot observations), and behavioural mapping. These tools are adopted in order to analyse the patterns of stationary uses of the MK EPN. These tools are unobtrusive observational methods that allow associating the design characteristics of the environment with the occupants' behavioural information while recording location and time (Bechtel \& Zeisel, 1987; Goličnik Marušic, 2016; Hanan, 2017; Whyte, 1980). Videography was complementary to behavioural mapping and a standalone method to record behaviours in crowded environments as previously adopted (Wang et al., 2016). The initial phase of behavioural mapping involves the extensive observation of the designed setting, the development of a base map, and the classification of the types of activities to be observed (Goličnik Marušic, 2016; Rasidi, Jamirsah, \& Said, 2012). The observed activities are then recorded on a GIS platform (Tammikakul \& Raksawin, 2019) and rendered through different types of maps and tables. This study applies the Dot Distribution Map to visualise the occurrence and patterns of stationary activities. The choice of these methods was 
influenced by the seminal work of William H. Whyte and Jan Gehl (Gehl, 1987; Whyte, 1980). More recent studies apply behavioural mapping by focussing on parks (Ghavampour, Del Aguila, \& Vale, 2017), urban streets (Elsheshtawy, 2013; Mehta, 2009), informal street markets (Sun, Bell, Scott, \& Qian, 2019), or public squares (Cheshmehzangi \& Heath, 2017) as behavioural settings.

\subsection{Data Collection}

Data collection was organised into two phases. The first one consisted of the development of the MK EPN area base map. Data were collected from the Outline Zoning Plan (OZP) of Hong Kong (Chapter 131, Laws of Hong Kong), recorded on the GIS data set, and integrated with primary spatial data of the EPN design collected on site. The second phase comprised the collection of data regarding stationary uses, which involved recording locational and categorical information on stationary activities (such as sitting and standing) of the occupants. The on-site observations were recorded during ten site visits from October to December 2018, as mild-climate months. The extensive on-site visits were set in order to cover different weather conditions. Sunday was selected as the observation day, primarily because it was the MDWs' weekly day off and government offices remained closed. The observations were made from 3 p.m. to 4 p.m., which is a recognised peak time for MDWs' social activities in Hong Kong (Law, 2001). The data collection protocol followed the walk-through method (Elsheshtawy, 2013), consisting of a pre-defined walking itinerary that covered the entire EPN. Data consistency and trustworthiness were achieved using videography for recording observations. Stationary activities were coded as data points on the EPN base map on GIS. The stationary activities were distinguished as individual (e.g., standing or sleeping), social activities (Gehl, 1987), or production-oriented activities (e.g., preparing food). The categorisation of stationary activities types was informed by relevant literature on MDWs' leisure activities (Law, 2001; Tillu, 2011). The total recorded behavioural observations are 14,765.

\subsection{Limitations of Methodology}

The following are the limitations associated with the methodology: First, the case study focussed on the EPN in MK. Other forms of public spaces, which may show similar phenomena were not selected. Second, walking activities were not considered for the data collection. Third, due to the dynamic nature of the activities and overcrowded space conditions, the stationary activities category is unlikely to fully represent the actions that the MDWs perform. An investigation of the location choice for these stationary activities is outside the scope of this study.

\subsection{Results}

The 14,765 recorded stationary activities were reported through the Dot Distribution Map (Fig. 2) to visualise the activity density across the MK EPN during the ten site visits. The overall activity data consisted of the population number and density (Table 1). The average 
number of observed stationary activities is 1476.5, the highest population is observed during rainy conditions (1642 observations), wherein it recorded about a 10\% increase from the average. The average occupancy follows a similar trend. The entire EPN registered an average occupancy of 0.41 person $/ \mathrm{m}^{2}$. Although this remains constant throughout the observation period, during rainy weather, the total occupancy reached 1642 persons, which is equal to 0.45 person $/ \mathrm{m}^{2}$ or about $2 \mathrm{~m}^{2} /$ person.

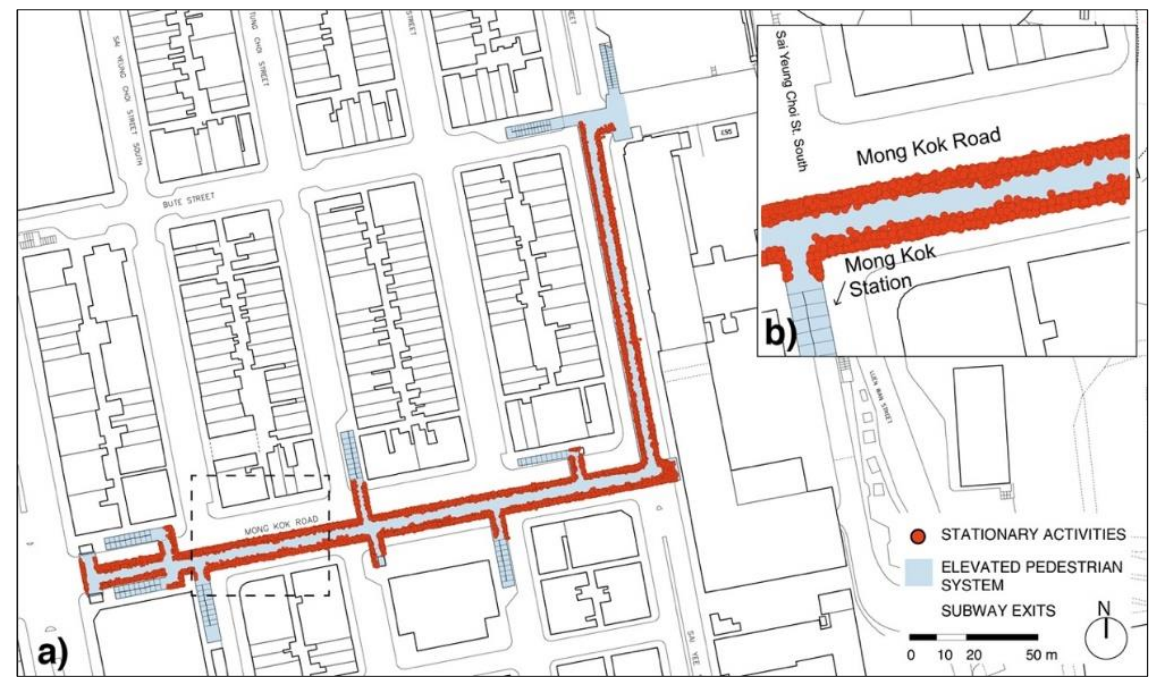

Fig. 2: Dot Distribution Map of Stationary activities in the EPN (Source: Caterina Villani and Cheng Yuk Ming)

Table 1. Activities and density per observation period

\begin{tabular}{|c|c|c|c|}
\hline Period & Weather Condition & Observations & Density [person $/ \mathrm{m}^{2}$ ] \\
\hline Day 1 & $28^{\circ} \mathrm{C}$, Sunny day & 1470 & 0.41 \\
\hline Day 2 & $25^{\circ} \mathrm{C}$, Cloudy day & 1459 & 0.40 \\
\hline Day 3 & $25^{\circ} \mathrm{C}$, Cloudy day & 1512 & 0.42 \\
\hline Day 4 & $24^{\circ} \mathrm{C}$, Sunny day & 1460 & 0.40 \\
\hline Day 5 & $24^{\circ} \mathrm{C}$, Cloudy day & 1493 & 0.41 \\
\hline Day 6 & $24^{\circ} \mathrm{C}$, Cloudy day & 1405 & 0.39 \\
\hline Day 7 & $24^{\circ} \mathrm{C}$, Cloudy day & 1560 & 0.43 \\
\hline Day 8 & $19^{\circ} \mathrm{C}$, Rainy day & 1642 & 0.45 \\
\hline Day 9 & $19^{\circ} \mathrm{C}$, Cloudy day & 1441 & 0.40 \\
\hline \multirow[t]{2}{*}{ Day 10} & $15^{\circ} \mathrm{C}$, Cloudy day & 1323 & 0.36 \\
\hline & Average & 1476.5 & 0.41 \\
\hline
\end{tabular}

(Source: Caterina Villani)

The stationary activities were further analysed through the categorisation of activities according to type. This was done through snapshot observations (Fig. 3, Table 2). In the EPN, the preferred activities were social (90\%), followed by individual $(8 \%)$ and production- 
oriented (2\%). Among these macro-categories, MDWs preferred to chat (87\%) and stand $(5 \%)$ as social and individual activities respectively.
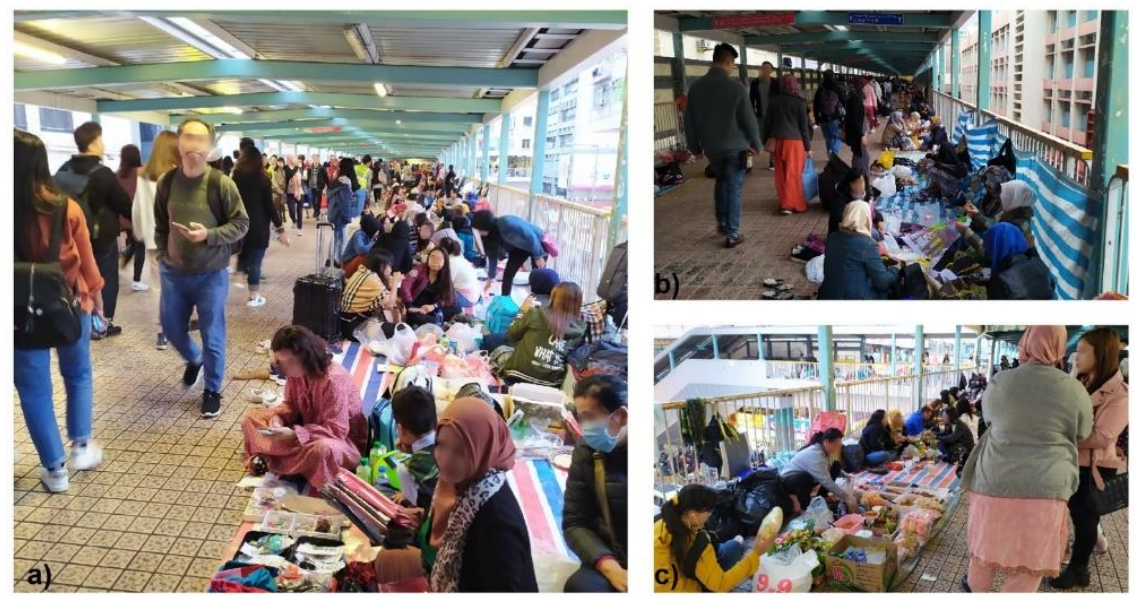

Fig. 3: a) Snapshot of stationary activities in the EPN Part 1. b) Snapshot of stationary activities in Part 2. c) Snapshot of MDWs preparing food

(Source: Gianni Talamini)

Table 2. Types of activities per observation period

\begin{tabular}{|c|c|c|c|c|c|c|c|}
\hline \multirow[t]{2}{*}{ Period } & \multicolumn{2}{|c|}{ Individual } & \multicolumn{4}{|c|}{ Social } & \multirow{2}{*}{$\begin{array}{c}\begin{array}{c}\text { Production- } \\
\text { oriented }\end{array} \\
\text { Preparing food }\end{array}$} \\
\hline & $\begin{array}{l}\text { Laying } \\
\text { down }\end{array}$ & Standing & Chatting & Singing & $\begin{array}{l}\text { Taking a } \\
\text { selfie }\end{array}$ & $\begin{array}{l}\text { Sharing } \\
\text { food }\end{array}$ & \\
\hline Day 1 & $6 \%$ & $4 \%$ & $82 \%$ & $1 \%$ & $1 \%$ & $2 \%$ & $4 \%$ \\
\hline Day 2 & $2 \%$ & $5 \%$ & $90 \%$ & $0 \%$ & $1 \%$ & $2 \%$ & $1 \%$ \\
\hline Day 3 & $3 \%$ & $4 \%$ & $88 \%$ & $0 \%$ & $1 \%$ & $2 \%$ & $2 \%$ \\
\hline Day 4 & $5 \%$ & $4 \%$ & $85 \%$ & $0 \%$ & $1 \%$ & $2 \%$ & $2 \%$ \\
\hline Day 5 & $4 \%$ & $4 \%$ & $88 \%$ & $0 \%$ & $1 \%$ & $2 \%$ & $2 \%$ \\
\hline Day 6 & $3 \%$ & $3 \%$ & $90 \%$ & $0 \%$ & $0 \%$ & $2 \%$ & $2 \%$ \\
\hline Day 7 & $1 \%$ & $5 \%$ & $90 \%$ & $0 \%$ & $1 \%$ & $2 \%$ & $1 \%$ \\
\hline Day 8 & $1 \%$ & $4 \%$ & $90 \%$ & $0 \%$ & $1 \%$ & $2 \%$ & $2 \%$ \\
\hline Day 9 & $3 \%$ & $5 \%$ & $86 \%$ & $0 \%$ & $1 \%$ & $3 \%$ & $2 \%$ \\
\hline Day 10 & $1 \%$ & $10 \%$ & $85 \%$ & $0 \%$ & $1 \%$ & $2 \%$ & $2 \%$ \\
\hline Average & $3 \%$ & $5 \%$ & $87 \%$ & $0 \%$ & $1 \%$ & $2 \%$ & $2 \%$ \\
\hline Total & & & & & $90 \%$ & & $2 \%$ \\
\hline
\end{tabular}

(Source: Caterina Villani)

As it emerges from the Kernel Density Map (Fig. 4), and from the snapshot observations (Fig. 3), the occupancy level is higher near specific features of the EPN and close to specific activities. This association was analysed by subdividing the total EPN area into: Part 1 and Part 2 of the EPN, and the railing area (Fig 5., Table 3). Additionally, the occupancy in the $1 \mathrm{~m}$ buffer from production-oriented activities was also examined for each observation day. 
Both Part 1 and Part 2 of the EPN show an average density of about 0.40 person $/ \mathrm{m}^{2}$, which is consistent with the total area density (Table 3). During rainy weather, Part 1 shows a slightly higher density $\left(0.50\right.$ person $\left./ \mathrm{m}^{2}\right)$ compared to Part 2 . One explanation is that Part 1 is wider $(8.5 \mathrm{~m})$ than Part $2(5.5 \mathrm{~m})$, and hence can accommodate a higher population without affecting the pedestrian flow. Although this flow was not counted, the snapshot observations recorded that activities cluster at both sides of the walkway space, leaving a middle path for pedestrians on the move. The effective space occupied by stationary activities was confined to the $2 \mathrm{~m}$ offset from each side of the railing (Fig. $3 \mathrm{a}$ ). This area registered an extremely high occupancy of $0.96 \mathrm{person} / \mathrm{m}^{2}$. Finally, stationary behaviours are highly clustered $\left(1.25\right.$ person $\left./ \mathrm{m}^{2}\right)$ near MDWs involved in food production activities (Table 3).
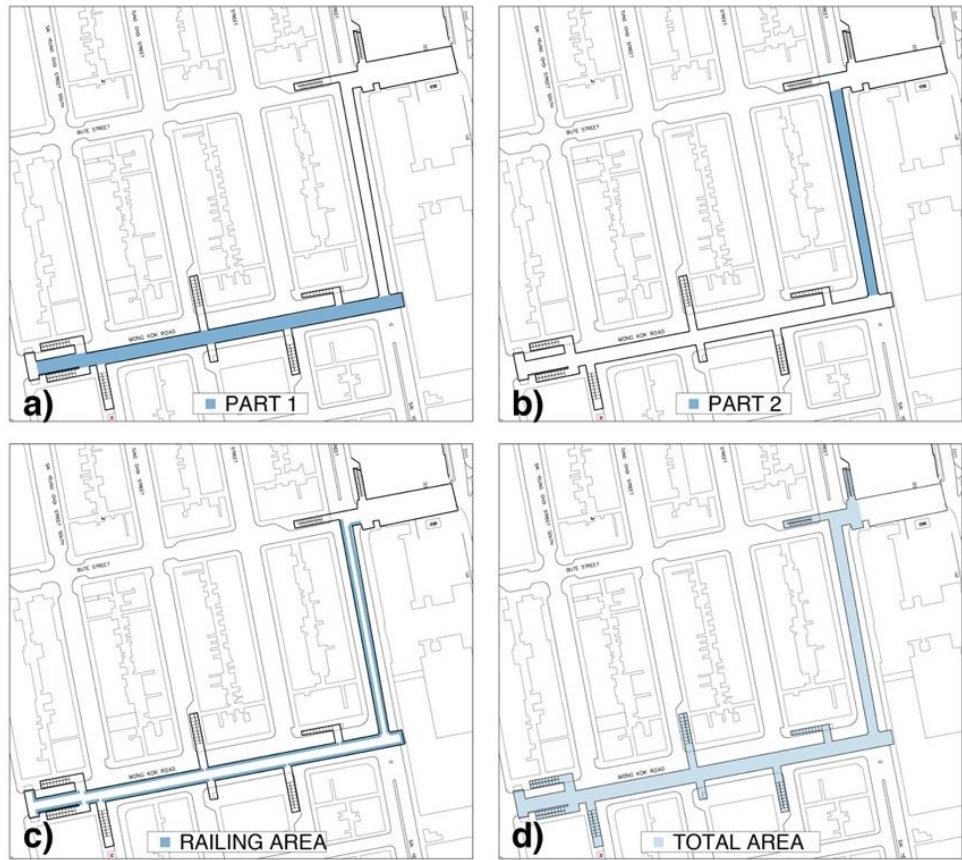

Fig. 5: a) the EPN part 1. b) The EPN part 2. c) The railing space (2 $\mathrm{m}$ offset) d) Total EPN area (Source: Caterina Villani)

Table 3. Activities' density per spatial feature

\begin{tabular}{lccllc}
\hline & Part 1 & Part 2 & $\begin{array}{l}\text { Railing } \\
\text { area }\end{array}$ & $\begin{array}{l}\text { Food } \\
\text { preparation } \\
\text { area }\end{array}$ & $\begin{array}{c}\text { Total } \\
\text { Area }\end{array}$ \\
\hline Day 1 & 0.42 & 0.39 & 0.96 & 1.38 & 0.41 \\
Day 2 & 0.45 & 0.30 & 0.95 & 1.17 & 0.40 \\
Day 3 & 0.43 & 0.44 & 0.99 & 1.43 & 0.42
\end{tabular}


Villani, C., \& Talamini, G. / Asian Journal of Environment-Behaviour Studies (ajE-Bs), 5(15) Jan / Apr 2020 (pp.57-72)

\begin{tabular}{llllll} 
Day 4 & 0.42 & 0.39 & 0.97 & 1.31 & 0.40 \\
Day 5 & 0.45 & 0.37 & 0.98 & 1.38 & 0.41 \\
Day 6 & 0.43 & 0.33 & 0.91 & 1.33 & 0.39 \\
Day 7 & 0.47 & 0.42 & 1.01 & 1.51 & 0.43 \\
Day 8 & 0.50 & 0.41 & 1.04 & 0.96 & 0.45 \\
Day 9 & 0.43 & 0.35 & 0.91 & 1.19 & 0.40 \\
Day 10 & 0.43 & 0.31 & 0.82 & 0.84 & 0.36 \\
Average & $\mathbf{0 . 4 4}$ & $\mathbf{0 . 3 7}$ & $\mathbf{0 . 9 6}$ & $\mathbf{1 . 2 5}$ & $\mathbf{0 . 4 1}$ \\
\hline \multicolumn{5}{l}{ (Source: Caterina Villani) }
\end{tabular}

\subsection{Discussion}

The present study found that, during the weekends in Hong Kong, the publicly-managed MK EPN hosts stationary activities performed primarily by MDWs which coexist with the originally intended purpose of the EPN - catering to high transit-generated pedestrian flow. In the case of the MK EPN the density of observed stationary activities is higher than previous empirical findings in other areas of Hong Kong (Tillu, 2011; Villani et al., 2019). In non-rainy conditions, the average density is $0.41 \mathrm{person} / \mathrm{m}^{2}$, which also corresponds to the entitled open space per person quota by the Hong Kong planning standard guidelines (HKPSG). When considering only the area effectively occupied by the stationary activities, the spatial occupation is as high as about 1 person $/ \mathrm{m}^{2}$.

The density's peak is observable during rainy weather conditions, wherein the occupancy increases by $12.6 \%$, almost reaching $2 \mathrm{~m}^{2} /$ person. Noticeably, canopies play a vital role in the climatic conditions of Hong Kong, where the average number of days with rainfall (calculated for the period from 1981 to 2010) is 137.63, and where the monthly mean of daily temperature exceeds $25 \mathrm{deg}$. C for 6 months a year (from April to October).

The recorded stationary activity types are not significantly diverse, with socially oriented ones being predominant (90\%). The high percentage of social activities found in the EPN, such as chatting, might indicate the importance of large groups and social activities for MDWs (Law, 2001), and the need for public spaces to accommodate them. The observed activities related to the use of cellular phones (self-photographing) are constantly occurring in $1 \%$ of the cases, being relatively low when compared to their normal rate of occurrence in contemporary public realms (Hatuka \& Toch, 2016). Moreover, the space designed for pedestrian movements is used for resting by an average $3 \%$ of individuals that lay down on blankets unfolded on the ground. The literature consistently reported such behaviour, as well as the habit to define the space with cardboards (Law, 2001).

The presence of incidental seating conditions (railings) and food-related activities proved to be fostering stationary activities in the EPN. It is observed that food-oriented activities are the strongest clustering factor, confirming previous studies on the importance of food for social interaction (Mehta, 2009; Whyte, 1980; Zordan, Talamini, \& Villani, 2019). These results are aligned with previous studies that found the above conditions together with the presence of covered space (as the EPN is) as a significant variable in supporting stationary activities (Mehta, 2009; Villani et al., 2019; Whyte, 1980). The occupancy pattern is mostly homogenous in the two orthogonal sections of the EPN. The occupancy variation 
in Part 1 of the EPN could be explained by its greater number of public (toilets) and commercial services (Fig.1) catering to MDWs in the proximity of MK road, as it appeared from the on-site observations. Similar clustering near migrant-catering commercial facilities are observed in other Asian cities (Elsheshtawy, 2013; Muniandy, 2015; Ostertag, 2016).

It may be appropriate to evaluate the observed maximum occupancy of 0.45 person $/ \mathrm{m}^{2}$ (during rainy weather) as the EPN's stationary activities upper limit capacity without the inconvenience or disruption of pedestrian movements. Nevertheless, although the EPN provides a decent supply to the lack of available public open space, it is certainly not the most ideal location for stationary uses, as the density of these activities may hinder mobility.

Hong Kong's GSPS were informed by modern standards and developed under a hegemonic engineering-oriented logic of functional optimization of mobility flows, without considerations about their possibility to host stationary uses. This study stands with recent literature in demonstrating the limits of such an approach, postulating that informality offers an understanding of the lack of formal answers to a factual demand (Talamini \& Pires Ferreira, 2019). Despite a growing body of literature and civic and professional organizations advocating for a radical change in the approach to the design and planning of GSPS, the rigid organization of the government structure - namely the entanglement of the city's bureaucratic system in problems of coordination (W. F. Lam, 2005) - implies that Hong Kong may not experience such a radical reform in the near future. Nevertheless, the rigidity of the bureaucratic system tends to produce spaces with similar features over a large time span, contributing to the formation of peculiar landscapes and thereby to strengthening the local identity, which may be shaped by such persistent cultural attributes. Subsequently, the Sunday gathering of MDWs on the EPNs is not only relevant as a process of informal reclamation of a corridor (from Latin currere "to run") as an public open space, it is also relevant as a contribution in the process of placemaking and the shaping of culturally rich districts such as MK.

This study has several limitations. Further research may consider a larger number of mobility-oriented case studies backed with space preference or ethnographic surveys. This would culminate in more robust and in-depth results. Recording walking activities, for example through cordon counts, might provide insights on the synergistic variation between pedestrian flow and activities in mobility-oriented spaces. Finally, trustworthiness of stationary data collection in overcrowded linear small urban spaces might be improved through multiple-fixed standpoint observations.

\subsection{Conclusion and Recommendations}

In high-density urban areas of Asia, the continuous expansion of GSPS provides space for an informal answer to the chronic lack of public open space. By focusing on the case of an EPN, this study contributed to the limited literature on the impact of GSPS on public space provision for stationary uses in the Asian context. In Hong Kong, the study area of this article, the elevated branched network is an opportunity for disadvantaged social groups, such as the MDWs, to perform stationary activities during their day off. 
This study, analysing the stationary activities $(n=14,765)$ during the weekends - peak days for stationary activities - on the EPN of MK, provided new empirical evidence about mobility-oriented spaces having the potential to become places of social engagement and interaction among users performing stationary activities. Specifically: (1) the average number of MDWs recorded among 10 days of observation was 1476.5; the average density of the EPN space occupation ( 0.41 person $\left./ \mathrm{m}^{2}\right)$, when excluding the area used for walking, this reaches 0.96 person $/ \mathrm{m}^{2} ;$; 2 during rainy periods, the occupancy rate increases by $12.6 \%$; (3) EPNs host a range of stationary activities which are mainly socially-oriented and related to MDWs engaging in conversation, food preparation, and food consumption; (4) behavioural observations highlight common patterns of occupancy that appear to be correlated with particular external factors, such as spatial layout, distance to accesses, proximity to public services, and garbage collection systems; and also appears to be correlated with internal factors, such as the location of production-oriented activities, the highest occupation density $\left(1.25\right.$ person $\left./ \mathrm{m}^{2}\right)$ being observed near food-oriented activities; (5) the observed capacity of the EPN to concurrently host stationary and mobility activities appears to have reached its upper limit in the cases of the observed periods.

The findings suggest the need for a more responsive and inclusive approach to the design of elevated pedestrian networks which takes into account stationary activities. They confirm that covered areas providing usable public open space in case of adverse weather condition are of vital importance in cities, such as Hong Kong, characterised by humid subtropical climate and scarcity of public spaces. This study argues for planning and designing inclusive social realms able to increase the wellbeing of disadvantaged social groups. Furthermore, this study advocates a flexible design of mobility spaces that enable them to easily upgrade to places of social engagement, rather than exclusively serve mobility functions. However, this may require structural changes in the production of public open spaces, which may need calling the bureaucratic system into question and renegotiating the governmental policy priorities. Definitely, the MDWs' informal appropriation of spaces originally designed and intended for serving mobility functions is challenging the way in which these spaces are conceived and it is relevant for its capacity to provide alternative scenarios to the top-down ones that are presently endowed. Moreover, the Sunday gatherings of MDWs - and their synergistic relationship with the walkways - is a culturally relevant phenomenon, which contributes to placemaking, cultural diversity, and the local identity of Hong Kong. The appropriation of the EPNs by MDWs not only highlights the urgency of increasing the provision of public open spaces, it also reveals the significant economic inequality, thus implicitly appealing for higher social and spatial justice.

\section{Acknowledgments}

This research was financially supported by a grant from City University of Hong Kong (project No. 7004965). We thank Cheng Yuk Ming for his assistance in data collection. 
Villani, C., \& Talamini, G. / Asian Journal of Environment-Behaviour Studies (ajE-Bs), 5(15) Jan / Apr 2020 (pp. 57-72)

\section{References}

Agyeman, J., \& Zavestoski, S. (2015). Incomplete streets: processes, practices, and possibilities. Oxon: Routledge.

Bechtel, R., \& Zeisel, J. (1987). Observation: the world under a glass. In R. Bechtel, R. Marans, \& W. Michelson (Eds.), Methods in Environmental and Behavioral Research. New York: Van Nostrand Reinhold.

Cheshmehzangi, A., \& Heath, T. (2017). Effects of Temporary Markets on Spatial Inter-relations: A behavioural analysis of a public realm in the UK. Journal of ASIAN Behavioural Studies, 2(3), 41. https://doi.org/10.21834/jabs.v2i3.190

Corbett, M. J., Xie, F., \& Levinson, D. (2009). Evolution of the Second-Story City: The Minneapolis Skyway System. Environment and Planning B: Planning and Design, 36(4), 711-724. https://doi.org/10.1068/b34066

Cui, J., Allan, A., \& Lin, D. (2013). The development of grade separation pedestrian system: A review. Tunnelling and Underground Space Technology, 38, 151-160. https://doi.org/10.1016/j.tust.2013.06.004

Cui, J., Allan, A., Taylor, M. A. P., \& Lin, D. (2013). Developing Shanghai Underground Pedestrian System Under Urbanization: Mobility, Functionality and Equity. Journal of Architecture and Urbanism, 36(4), 283-297. https://doi.org/10.3846/20297955.2012.752933

Elsheshtawy, Y. (2013). Where the sidewalk ends: Informal street corner encounters in Dubai. Cities, 31, 382393. https://doi.org/10.1016/j.cities.2012.12.001

Gehl, J. (1987). Life Between Buildings: Using Public Space. New York: Van Nostrand Reinhold. https://doi.org/10.1016/j.progress.2005.01.001

Ghavampour, E., Del Aguila, M., \& Vale, B. (2017). GIS mapping and analysis of behaviour in small urban public spaces. Area, 49(3), 349-358. https://doi.org/10.1111/area.12323

Goličnik Marušic, B. (2016). Discrepancy between likely and actual occupancies of urban outdoor places. Urban Forestry and Urban Greening, 18, 151-162. https://doi.org/10.1016/j.ufug.2016.06.001

Hanan, H. (2017). Every Day Practices and Experiential Urban Space. Asian Journal of Environment-Behaviour Studies, 2(5), 27. https://doi.org/10.21834/aje-bs.v2i5.220

Harris, A. (2018). Engineering Formality: Flyover and Skywalk Construction in Mumbai. International Journal of Urban and Regional Research, 42(2), 295-314. https://doi.org/10.1111/1468-2427.12525

Hatuka, T., \& Toch, E. (2016). The emergence of portable private-personal territory: Smartphones, social conduct and public spaces. Urban Studies, 53(10), 2192-2208. https://doi.org/10.1177/0042098014524608

HKSAR Census and Statistics Department. (2016). 2016 Population By-census.

Lam, P., \& Kung, F. (2004). Innovative and sustainable construction for a footbridge system in congested mongkok, hong kong. HKIE Transactions Hong Kong Institution of Engineers, 11(1), 15-20. https://doi.org/10.1080/1023697X.2004.10667938

Lam, W. F. (2005). Coordinating the government bureaucracy in Hong Kong: An institutional analysis. Governance, 18(4), 633-654. https://doi.org/10.1111/j.1468-0491.2005.00295.x 
Villani, C., \& Talamini, G. / Asian Journal of Environment-Behaviour Studies (ajE-Bs), 5(15) Jan / Apr 2020 (pp. 57-72)

Law, L. (2001). Home cooking: Filipino women and geographies of the senses in Hong Kong. Ecumene, 8(Figure 1), 264-283.

Law, L. (2002). Defying Disappearance: Cosmopolitan Public Spaces in Hong Kong. Urban Studies, 39(9), 16251645. https://doi.org/10.1080/00420980220151691

Maitland, B. (1992). Hidden cities: The irresistible rise of the North American interior city. Cities, 9(3), 162-169. https://doi.org/10.1016/0264-2751(92)90012-T

Mehta, V. (2009). Look closely and you will see, listen carefully and you will hear: Urban design and social interaction on streets. Journal of Urban Design, 14(1), 29-64. https://doi.org/10.1080/13574800802452658

Muniandy, P. (2015). Informality and the politics of temporariness: Ethnic migrant economies in Little Bangladesh and Little Burma in Kuala Lumpur, Malaysia. International Sociology, 30(6), 561-578. https://doi.org/10.1177/0268580915605649

Nikolaeva, A., Adey, P., Cresswell, T., Lee, J. Y., Nóvoa, A., \& Temenos, C. (2019). Commoning mobility: Towards a new politics of mobility transitions. Transactions of the Institute of British Geographers, 44(2), 346-360. https://doi.org/10.1111/tran.12287

Ostertag, E. (2016). Transitory community hubs: How temporary migration transforms a neighbourhood in Singapore. City, 20(1), 116-129. https://doi.org/10.1080/13604813.2015.1096058

Rasidi, M. H., Jamirsah, N., \& Said, I. (2012). Urban Green Space Design Affects Urban Residents' Social Interaction. Procedia - Social and Behavioral Sciences. https://doi.org/10.1016/j.sbspro.2012.12.242

Robertson, K. A. (1993). Pedestrianization strategies for downtown planners skywalks versus pedestrian malls. Journal of the American Planning Association, 59(3), 361-370. https://doi.org/10.1080/01944369308975887

Rossini, F. (2019). Temporary urban intervention in the vertical city: a place-making project to re-activate the public spaces in Hong Kong. Journal of Urban Design, 24(2), 305-323. https://doi.org/10.1080/13574809.2018.1507674

Sun, Z., Bell, S., Scott, I., \& Qian, J. (2019). Everyday use of urban street spaces: the spatio-temporal relations between pedestrians and street vendors: a case study in Yuncheng, China. Landscape Research, 00(00), 1-18. https://doi.org/10.1080/01426397.2019.1646231

Talamini, G., \& Pires Ferreira, D. (2019). An informal transportation as a feeder of the rapid transit system. Spatial analysis of the e-bike taxi service in Shenzhen, China. Transportation Research Interdisciplinary Perspectives, 1 , 100002. https://doi.org/10.1016/J.TRIP.2019.100002

Tammikakul, P., \& Raksawin, K. (2019). The Pattern of Activity Analysis by GIS in Chiang Mai Public Plaza, Thailand. Asian Journal of Environment-Behaviour Studies, 4(13), 30. https://doi.org/10.21834/aje-bs.v4i13.346

Tan, Z., \& Xue, C. Q. L. (2014). Walking as a Planned Activity: Elevated Pedestrian Network and Urban Design Regulation in Hong Kong. Journal of Urban Design, 19(5), 722-744.

Tang, B. (2017). Is the distribution of public open space in Hong Kong equitable, why not? Landscape and Urban Planning, 161, 80-89. https://doi.org/10.1016/j.landurbplan.2017.01.004

Terranova, C. N. (2009). Ultramodern Underground Dallas: Vincent Ponte's Pedestrian-Way as Systematic Solution to the Declining Downtown. Urban History Review, 37(2), 18. https://doi.org/10.7202/029574ar 
Tillu, J. S. (2011). Spatial empowerment: the appropriation of public spaces by Filipina domestic workers in Hong Kong. Master Thesis, Massachusetts Institute of Technology. Retrieved from https://dspace.mit.edu/handle/1721.1/67244

UN-Habitat. (2013). Streets as public spaces and drivers of urban prosperity. Nairobi: UN-Habitat.

Villani, C. (2018). CBD: A new porosity. In C. Yuan (Ed.), Walkable Cities in High Density China: Livable, Healthy and Sustainable (pp. 83-109). Shanghai: Tongji University Press.

Villani, C., Zordan, M., Talamini, G., \& Cheng, Y. H. (2019). Temporarily Pedestrianized Street in Hong Kong: Governmental Strategy of Implementation and Tactics of Appropriation by Foreign Domestic Workers. In Proceedings of the AESOP 2019 Congress Book of Papers (p. 2559). Venice: The AESOP 2019 Congress.

Von Schönfeld, K. C., \& Bertolini, L. (2017). Urban streets: Epitomes of planning challenges and opportunities at the interface of public space and mobility. Cities, 68(June 2016), 48-55.

https://doi.org/10.1016/j.cities.2017.04.012

Wan, S. W. S. (2010). The Role of the Skywalk System in the Development of Hong Kong's Central Business District. Ssrn. https://doi.org/10.2139/ssrn.1699686

Wang, W., Siu, K. W. M., \& Wong, K. C. K. (2016). The pedestrian bridge as everyday place in high-density cities: An urban reference for necessity and sufficiency of placemaking. Urban Design International, 21(3), 236-253. https://doi.org/10.1057/udi.2016.3

Whyte, W. H. (1980). The Social Life of Small Urban Spaces (12th print). New York: Project for Public Spaces. Retrieved from

https://www.worldcat.org/title/social-life-of-small-urban-spaces/oclc/907415693\&referer=brief_results

Xue, C. Q. L., Manuel, K. K., \& Chung, R. H. Y. (2001). Public space in the old derelict city area - a case study of Mong Kok, Hong Kong. Urban Design International, 6(1), 15-31. https://doi.org/10.1057/palgrave.udi.9000032

Yin, R. K. (1984). Applied social research methods series Case study research: Design and methods. London: SAGE Publications.

Zacharias, J., \& He, J. (2018). Hong Kong's urban planning experiment in enhancing pedestrian movement from underground space to the surface. Tunnelling and Underground Space Technology, 82(July), 1-8. https://doi.org/10.1016/j.tust.2018.07.025

Zordan, M., Talamini, G., \& Villani, C. (2019). The Association between Ground Floor Features and Public Open Space Face-To-Face Interactions: Evidence from Nantou Village, Shenzhen. International Journal of Environmental Research and Public Health, 16(24), 4934. https://doi.org/10.3390/ijerph16244934 